\title{
Individual gustatory reaction times to various groups of chemicals that provoke basic taste qualities
}

\author{
ZORAN BUJAS \\ Yugoslav Academy of Sciences and Arts, Zagreb, Yugoslavia \\ and \\ SILVIJA SZABO, DEAN AJDUKOVIĆ, and DRAGUTIN MAYER \\ University of Zagreb, Zagreb, Yugoslavia
}

\begin{abstract}
Reaction times (RTs) to four groups of substances that provoke different taste qualities were measured. Measurements for all substances with the same taste, equalized in perceived intensity and provoking a very strong taste, were made concurrently for each subject. The comparisons were made on the individual level. No significant differences in RTs to substances with the same taste quality were found. When the factor of perceived intensity is kept constant, no effect of the stimulus chemical composition on RTs seems to be present. RTs to stimuli with different tastes differ significantly, the shortest being to salt and the longest to bitter. The difference in RTs for sour and sweet substances is small, and the subjects were not all alike in terms of the order of RTs with respect to these stimuli.
\end{abstract}

Although by far the dominant part of total reaction time (RT) is attributable to the time of cortical processing events (Halpern, 1986), some significant differences in RTs to various taste substances imply that the time of receptor-organ events can also play a detectable role. In fact, some investigators, on the basis of their gustatory RT results, have made certain remarks concerning the similarity or dissimilarity in the receptor transduction process. But these RT comparisons have been limited to various salt and sweet substances (Yamamoto, Kato, Matsuo, Kawamura, \& Yoshida, 1985; Yamamoto \& Kawamura, 1984) or to a few stimuli that evoke a sour taste (Bujas, Szabo, Mayer, Ajduković, \& Vodanović, 1989). Also, in some of these studies, the different subjects have been stimulated by different substances, so that a great intervariability could have distorted the comparison results.

The purpose of the present study was to obtain, if possible, some information on the receptor transduction mechanism by comparing RTs to various typical substances with the same taste quality, with the same subjects being exposed to all the stimuli used. Because the taste RT for a substance varies widely with its taste intensity, it was necessary, within each group of substances and for each individual subject, to equalize perceived taste intensities carefully. To diminish the influence of each subject's intravariability from session to session, all RT

Correspondence may be sent to Silvija Szabo, Department of Psychology, Filozofski fakultet, University of Zagreb, Dj. Salaja 3, 41000 Zagreb, Yugoslavia. measurements for substances with the same taste quality were made concurrently. Moreover, to have a common reference point, the $\mathrm{RTs}$ to $1.0 \mathrm{M} \mathrm{NaCl}$ in all sessions were determined.

\section{METHOD}

\section{Apparatus and Stimuli}

Taste stimuli were applied to the anterior part of the tongue by a gravity flow system. To assure an initially uniform hydrodynamic pressure of the liquid against the tongue surface, a siphon container was used. From this container, the solution flowed through three channels at $6 \mathrm{ml} / \mathrm{sec}$ over a tongue area of about $7 \mathrm{~cm}^{2}$, eliciting, at contact, only a slight touch sensation. The stimulus duration time was $5 \mathrm{sec}$. The solutions were warmed to $38^{\circ} \mathrm{C}$.

For the recording of RTs, one electrode was located in the container and the other was attached under the subject's chin. At the moment the solution contacted the tongue surface, the alternating current of $5 \mu \mathrm{A}$ and $5 \mathrm{kHz}$ passed for $2 \mathrm{msec}$ through the subject. This short subliminal pulse activated an electronic chronometer. The subject, at the moment of taste recognition, stopped the chronometer by manual release of a switch.

All substances, except sucrose, were of a reagent grade, dissolved in distilled water; the solution concentrations are expressed in moles/liter.

\section{Procedure}

Four experienced subjects participated in the experiment, which was divided into four parts. In each part, which included several sessions, all solutions with the same taste quality were randomly applied. The RT measurements were made in the following order: salts, acids, bitter substances, and sweeteners. Obviously, the subjects were not informed regarding the chemical by which they were stimulated at a given moment. In each session, 8 to $10 \mathrm{RT}$ measurements for each substance were made, and the individual mean values are based on $\mathbf{3 5}$ to $\mathbf{5 0}$ trials for each stimulus. 
Table 1

Individual Reaction Times $(M \pm S D)$ to Equisalty Solutions of Five Salts

\begin{tabular}{lcccc} 
& \multicolumn{4}{c}{ Subjects } \\
\cline { 2 - 5 } Compounds & $\mathrm{A}$ & $\mathrm{B}$ & $\mathrm{C}$ & $\mathrm{D}$ \\
\hline $\mathrm{NaCl}$ & $339 \pm 56.38$ & $445 \pm 68.67$ & $384 \pm 84.56$ & $579 \pm 83.57$ \\
$\mathrm{NH}{ }_{4} \mathrm{Cl}$ & $356 \pm 52.84$ & $451 \pm 47.15$ & $377 \pm 81.60$ & $588 \pm 95.14$ \\
$\mathrm{NaBr}$ & $332 \pm 58.91$ & $449 \pm 50.98$ & $374 \pm 92.48$ & $580 \pm 77.65$ \\
$\mathrm{LiCl}$ & $343 \pm 51.37$ & $434 \pm 85.09$ & $401 \pm 79.98$ & $577 \pm 70.07$ \\
$\mathrm{KCl}$ & $342 \pm 68.76$ & $450 \pm 55.89$ & $389 \pm 89.79$ & $580 \pm 69.86$ \\
$M \pm S D$ & $342.4 \pm 8.73$ & $445.8 \pm 6.98$ & $385.0 \pm 10.70$ & $580.8 \pm 4.21$ \\
$S D / M$ & $2.55 \%$ & $1.57 \%$ & $2.78 \%$ & $0.72 \%$ \\
\hline
\end{tabular}

The taste intensity of the solutions of different compounds with the same taste quality was equalized by the method of limits with numerous ascending and descending series. The subjects, during the RT trials, did not perceive any difference in the taste intensity of previously matched stimuli.

\section{RESULTS}

\section{Reaction Times to Five Salts}

The salts were equalized in perceived intensity to that of $1.0 \mathrm{NaCl}$. The equisalty concentrations were: $1.5 \mathrm{KCl}$, $1.0 \mathrm{NaBr}, 1.0 \mathrm{LiCl}$, and $0.7 \mathrm{NH}_{4} \mathrm{Cl}$ for Subject $\mathrm{A}$; $1.3 \mathrm{KCl}, 1.0 \mathrm{NaBr}, 0.95 \mathrm{LiCl}$, and $0.8 \mathrm{NH}_{4} \mathrm{Cl}$ for Subject $\mathrm{B} ; 1.1 \mathrm{KCl}, 1.0 \mathrm{NaBr}, 1.0 \mathrm{LiCl}$, and $0.72 \mathrm{NH}_{4} \mathrm{Cl}$ for Subject C; $1.2 \mathrm{KCl}, 0.95 \mathrm{NaBr}, 0.95 \mathrm{LiCl}$, and $0.7 \mathrm{NH}_{4} \mathrm{Cl}$ for Subject D. All the concentrations provoked a very intense salty taste.

The individual RTs to the equisalty solutions of the five salts are given in Table 1. An analysis of variance (ANOVA) was performed to determine whether withinsubject significant RT differences in responses to the five chemical stimuli existed. The analysis revealed no significant differences across the compounds used. The $F$ ratios for Subjects $\mathrm{A}, \mathrm{B}, \mathrm{C}$, and $\mathrm{D}$ were as follows: $F_{\mathrm{A}}(4,200)=.8858, F_{\mathrm{B}}(4,204)=.6351, F_{\mathrm{C}}(4,216)=$ .7757 , and $F_{\mathrm{D}}(4,170)=.0495$.

The within-subject variability of the RT means for the five salts is very low. Evaluated in terms of $S D$, the variability ranges from $2.78 \%$ of the grand mean for Subject $C$ to only $0.72 \%$ of the grand mean for Subject $D$, showing that no consistent effect of the salt chemical composition on RT is present.

The RT variability of the individual subjects ranges from $13.6 \%$ for Subject D to $22.3 \%$ for Subject C. The average variation coefficient of $16.7 \%$ seems to be high, but what must be taken into consideration is that the RTs were obtained not in one, but in four or five sessions.

\section{Reaction Times to Four Acids}

The standard used in the matching procedure was $\mathrm{HCl}$, but owing to great differences in the sensitivities of our subjects to $\mathrm{HCl}$, the strong standard concentration had to be different: 0.034 for Subject A, 0.048 for Subject B, 0.06 for Subject C, and 0.065 for Subject D.

The equisour concentrations included 0.0453 citric acid, 0.061 tartaric acid, and $0.0313 \mathrm{H}_{2} \mathrm{SO}_{4}$ for Subject $\mathrm{A}$; 0.053 citric acid, 0.10 tartaric acid, and $0.07 \mathrm{H}_{2} \mathrm{SO}_{4}$ for Subject B; 0.057 citric acid, 0.075 tartaric acid, and 0.055 $\mathrm{H}_{2} \mathrm{SO}_{4}$ for Subject $\mathrm{C} ; 0.0875$ citric acid, 0.1575 tartaric acid, and $0.055 \mathrm{H}_{2} \mathrm{SO}_{4}$ for Subject D. These solutions provoked a very strong sour taste, but they still did not elicit any prickling or burning sensations.

Table 2 contains the individual RTs to the equisour solutions of the four acids. No significant differences in RTs across chemicals was present. The analysis yielded the following values: $F_{\mathrm{A}}(3,168)=.1039, F_{\mathrm{B}}(3,166)=.6262$, $F_{\mathrm{C}}(3,136)=.5000$, and $F_{\mathrm{D}}(3,136)=.2759$. The variability coefficients of the mean RTs to the four acids are very low, comparable to that observed for salts. The RT intravariability for the acid stimuli is on the average $16 \%$, varying from $14 \%$ for Subjects A and D to $19.5 \%$ for Subject C.

\section{Reaction Times to Two Bitter Substances}

As regards bitter substances, the RT measurements were made only to quinine sulfate $\left(\mathrm{QSO}_{4}\right)$ and quinine hydrochloride $(\mathrm{QHCl})$. For our subjects, other substances, such as caffeine, urea, and $\mathrm{MgSO}_{4}$, were attempted, but they proved to be not just bitter alone, or they were of

Table 2

Individual Reaction Times $(M \pm S D)$ to Equisour Solutions of Four Acids

\begin{tabular}{lcccc}
\hline & \multicolumn{4}{c}{ Subjects } \\
\cline { 2 - 5 } Compounds & A & B & C & D \\
\hline HCl & $524 \pm 72.12$ & $744 \pm 142.47$ & $486 \pm 95.58$ & $793 \pm 105.19$ \\
Citric acid & $529 \pm 81.71$ & $717 \pm 128.65$ & $496 \pm 115.67$ & $810 \pm 116.25$ \\
Tartaric acid & $525 \pm 69.89$ & $716 \pm 103.24$ & $481 \pm 93.24$ & $812 \pm 129.48$ \\
$\mathrm{H}_{2} \mathrm{SO}_{4}$ & $521 \pm 71.13$ & $709 \pm 98.99$ & $505 \pm 78.78$ & $809 \pm 99.82$ \\
$M \pm S D$ & $524.8 \pm 3.30$ & $721.5 \pm 15.42$ & $492.0 \pm 10.68$ & $806.0 \pm 8.76$ \\
$S D / M$ & $0.63 \%$ & $2.14 \%$ & $2.17 \%$ & $1.09 \%$ \\
\hline
\end{tabular}


a bitter taste clearly less intense than the taste of the solutions that provoked the other taste qualities.

The $\mathrm{QHCl}$ concentrations matched to a nearly saturated concentration of $\mathrm{QSO}_{4}(0.003)$ included 0.00523 for Subject A, 0.0129 for Subject B, 0.00588 for Subject C, and 0.0157 for Subject D.

Table 3 gives the RTs to the two equibitter solutions. The ANOVA showed that RT was not influenced by change in the stimulus compound: $F_{\mathrm{A}}(1,68)=.0085$, $F_{\mathrm{B}}(1,68)=.5200, F_{\mathrm{C}}(1,98)=.7487$, and $F_{\mathrm{D}}(1,78)=$ .0131 . The individual $\mathrm{RT}$ variability is on the average $19.2 \%$, somewhat higher than that for other taste substances.

We tried to complete these results by stimulating our subjects with a strong aqueous extract of the leaves of Artemisia absinthium. For 3 of the subjects it was possible to equalize this stimulus with $\mathrm{QSO}_{4}$ and $\mathrm{QHCl}$, but in somewhat lower concentrations. For 2 of these subjects RT to the extract was comparable to that for quinines, but for the 3rd it was significantly longer.

\section{Reaction Times to Four Sweeteners}

The sweeteners aspartame, Na-cyclamate, and $\mathrm{Na}$ saccharin were equalized in perceived sweetness with 1.0 sucrose. The aspartame was kindly supplied by NutraSweet Co. (Zug, Switzerland), and the saccharin by Pliva Co. (Zagreb).

The matched concentrations included 0.0043 aspartame, 0.051 cyclamate, and 0.0035 saccharin for Subject $A$; 0.005 aspartame, 0.035 cyclamate, and 0.012 saccharin for Subject B (for no apparent reason, aspartame was sweeter than saccharin to Subject B); 0.0079 aspartame, 0.024 cyclamate, and 0.0027 saccharin for Subject $C$; 0.0045 aspartame, 0.0232 cyclamate, and 0.00253 saccharin for Subject D.

Table 4 gives the RTs to the four equisweet solutions of sweeteners. The RT measurements were made in four sessions. The individual RT values are the means of 40 trials for each stimulus for each subject. The RT homogeneity of the applied sweeteners is greater than that observed for the substances with other taste qualities. The ANOVA performed on the RT data for the four sweeteners showed no significant effect due to the chemical composition of stimulus substances: $F_{\mathrm{A}}(3,156)=.0514$, $F_{\mathrm{B}}(3,156)=.3881, F_{\mathrm{C}}(3,156)=.0576$, and $F_{\mathrm{D}}(3,156)$ $=.0251$. The average individual RT variability is $13.8 \%$, ranging from $12.7 \%$ to $15.0 \%$; it is somewhat lower than that for other tastants.

This absence of any influence of the sweeteners' chemical composition on RTs is in some disagreement with the results of Yamamoto et al. (1985), who observed a significant RT variability among the 12 sweeteners they used. For this reason, to control the RT homogeneity observed in the means overall, we also analyzed our data as a function of the experimental sessions. Figure 1 presents data on such a fractional analysis, showing that the closeness of mean RT values for four sweeteners is not an accidental event. Figure 2 presents the RT results in the form of distribution curves, showing that not only the mean RTs for sweeteners but also the distribution forms of the particular RTs are close.

\section{DISCUSSION}

As the results show, the RTs to various substances with the same taste quality are, regardless of their chemical composition, very similar. The mean RT variability for the compounds with the same type of taste is $1.91 \%$ for salts, $1.51 \%$ for acids, $1.34 \%$ for two bitter substances, and $0.64 \%$ for sweeteners. When the factor of the perceived taste intensity of a taste quality is kept constant, no effect of the stimulus chemical composition seems to be present. Obviously, this statement applies only to the chemicals used.

Table 3

Reaction Times $(M \pm S D)$ to Equibitter Solutions of Two Substances

\begin{tabular}{ccccc}
\multicolumn{5}{c}{ Reaction Times $(M \pm S D)$ to Equibitter Solutions of Two Substances } \\
\cline { 2 - 5 } Compounds & A & B & C & D \\
\hline QSO, & $974 \pm 226.56$ & $1169 \pm 182.34$ & $878 \pm 150.74$ & $1113 \pm 206.97$ \\
QHCl & $979 \pm 203.74$ & $1129 \pm 176.14$ & $905 \pm 207.57$ & $1119 \pm 215.39$ \\
$M \pm S D$ & $976.5 \pm 3.54$ & $1149.0 \pm 28.28$ & $891.5 \pm 19.09$ & $1116.0 \pm 4.24$ \\
$S D / M$ & $0.36 \%$ & $2.46 \%$ & $2.14 \%$ & $0.38 \%$ \\
\hline
\end{tabular}

Table 4

Reaction Times $(M \pm S D)$ to Equisweet Solutions of Four Sweeteners

\begin{tabular}{lcccc}
\hline & \multicolumn{4}{c}{ Subjects } \\
\cline { 2 - 5 } Compounds & A & B & C & D \\
\cline { 2 - 5 } Sucrose & $597 \pm 96.87$ & $798 \pm 102.24$ & $498 \pm 71.50$ & $746 \pm 107.87$ \\
Aspartame & $600 \pm 94.31$ & $800 \pm 98.58$ & $504 \pm 67.19$ & $746 \pm 91.01$ \\
Cyclamate & $595 \pm 85.01$ & $780 \pm 95.21$ & $501 \pm 76.68$ & $745 \pm 107.08$ \\
Saccharin & $593 \pm 82.11$ & $785 \pm 105.62$ & $502 \pm 66.85$ & $750 \pm 93.43$ \\
$M \pm S D$ & $596.3 \pm 2.99$ & $790.8 \pm 9.78$ & $501.3 \pm 2.50$ & $746.8 \pm 2.22$ \\
$S D / M$ & $0.50 \%$ & $1.24 \%$ & $0.50 \%$ & $0.30 \%$ \\
\hline
\end{tabular}




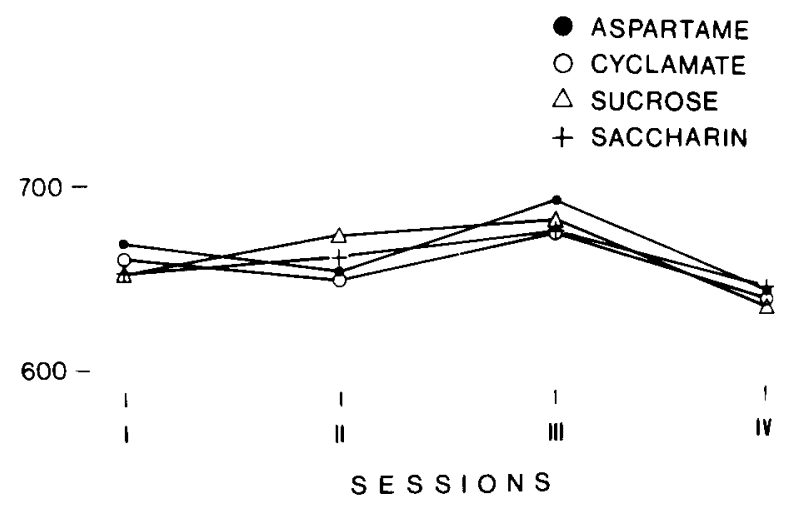

Figure 1. Reaction times (in msec) to four sweeteners (ordinate) in the function of sessions (abscissa). Fractional mean values for four subjects.

Each total RT comprises the times relating to sensory transduction, afferent conduction, cortical events, efferent conduction, and response-organ events.

According to Beidler and Tonosaki (1985), the taste sensory transduction process includes, in the following order, stimulus transport, microvilli adsorption, cell messenger, membrane conformational change, membrane conductance change, receptor potential, synapse transmission, graded local potential, and nerve action potential. If the times of other events in each total RT were comparable, a significant difference in RTs could suggest a difference in the transduction process. However, the similarity in RTs does not necessarily imply that for a given taste quality a single type of receptor is responsible. Different receptor sites, encoding the same taste quality, could have similar transduction times.

In Beidler's models (1971), the salty taste is attributed to the binding of cations to the receptor sites, while the sour taste is the result of the binding of hydrogen ions. The anions in both cases are inhibitory, but in the case of the sour taste, the anions' decreasing of the positive

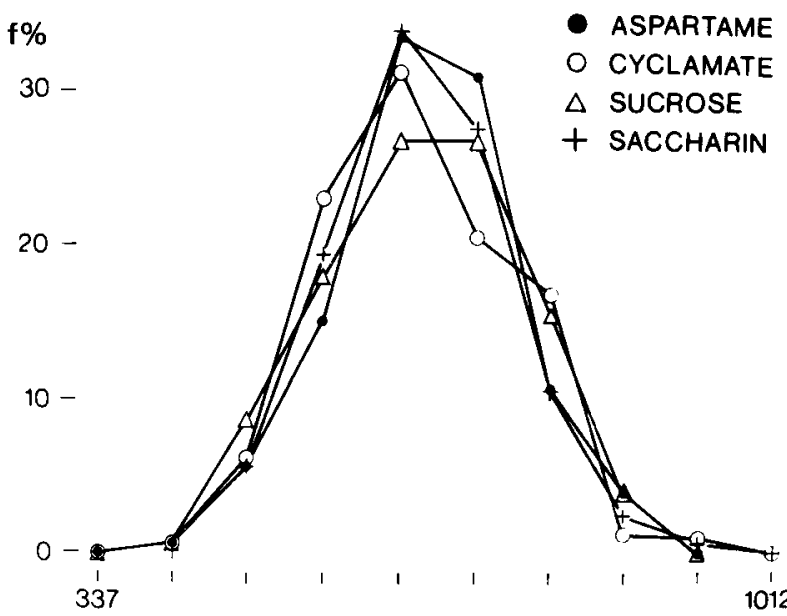

Figure 2. Distribution curves for RTs to four sweeteners. Each curve is based on 160 results ( 40 per subject) transformed according to the corresponding common mean value. membrane charge permits additional binding of hydrogen ions, which overcomes the anion inhibitory effect. Since the physical properties of stimulating ions are relatively simple, and the cation binding is not stereospecific, it could be assumed that the transduction mechanism is more or less independent of the variation in the stimulus composition.

In cross-adaptation studies, it has been found that adaptation to one acid raises the threshold for all other acids (Hahn, 1949) and that adaptation to $\mathrm{NaCl}$ decreases the taste magnitude of all the salts used (Smith \& McBurney, 1969), suggesting that different acids, as well as different salts, act on the same type of corresponding receptors. If the transduction mechanisms within salts and within acids were the same, then the RTs with respect to different chemicals within each taste could be similar. Our results obtained for salts and acids are in agreement with this assumption.

However, the stimulus molecules of sweet and bitter substances are more specific than salt and acid ions. The molecules of sweet and bitter substances are bound to the taste-receptor sites predominantly with hydrogen and van der Waal bonds, and the maximum hydrogen-bond strength occurs when the donator, acceptor, and $\mathrm{H}$ atom are colinear (Beidler \& Tonosaki, 1985). The great variety and stereospecificity of sweet and bitter molecules has even led to supposing a complementary receptor molecule for each kind of stimulus molecule.

Some cross-adaptation results are also in agreement with the supposition that the sweet and bitter tastes evoked by different compounds can be encoded on multiple receptor sites. Some bitter substances did not cross-adapt (McBurney, Smith, \& Shick, 1972), and the crossadaptation between sweeteners on the threshold and suprathreshold levels indicates that the sweet taste may be mediated by multiple receptor sites (Lawless \& Stevens, 1983; Schiffman, Cahn, \& Lindley, 1981).

Our results with sweet and bitter substances show only that the probable differences in the transduction process within these substances do not markedly influence the transduction time. The possibility that RTs can be similar even if the transduction processes are different shows that the RT approach is not completely appropriate for verifying whether a given taste quality is encoded by one or by several distinct sites. Only when the transduction mechanism is substantially different, as is the case, for instance, in the chemical and electrical stimulation of sour receptors, can such a difference be detected also in the corresponding RT (Bujas, 1980).

Unlike the constancy of RTs for substances with the same type of taste, the RT values for the compounds with different types of taste are dissimilar. The results with our subjects, expressed in terms of percentages relative to the RTs to $1.0 \mathrm{NaCl}$, are given in Figure 3. Since RTs to the substances with the same taste did not significantly differ, only the position of their mean values is shown.

Compared with the mean RTs to $\mathrm{NaCl}$, mean RTs to other tastants vary greatly among subjects. While, for in- 

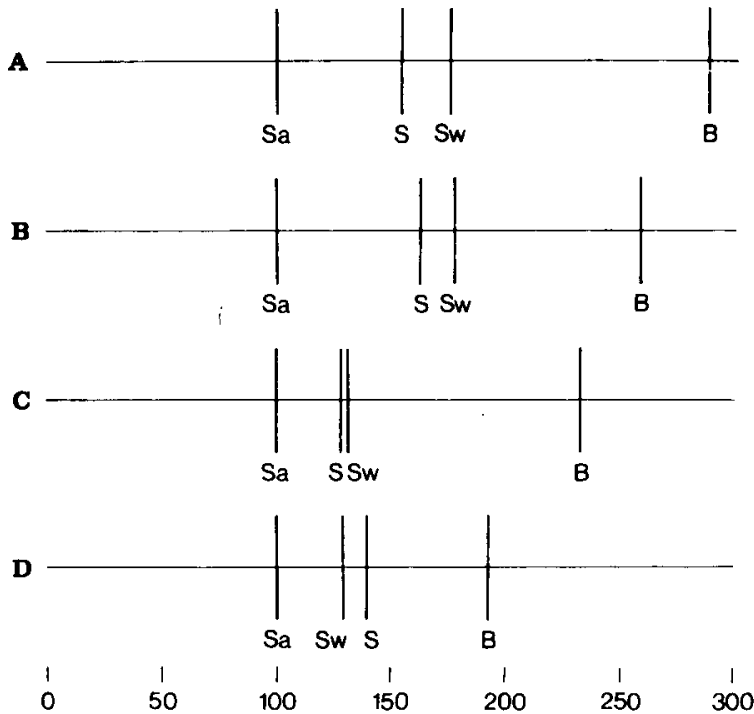

Figure 3. Mean reaction times to the group of substances with the same taste quality expressed in terms of percentage relative to mean RTs to $1.0 \mathrm{M} \mathrm{NaCl}$. Individual results for four subjects. Sa = salty, $\mathrm{S}=$ sour, $\mathbf{S w}=$ sweet, $\mathrm{B}=$ bitter.

stance, mean RT to bitter substances, for Subject A, is $188 \%$ longer than it is to $\mathrm{NaCl}$, for Subject $\mathrm{D}$ it is only 93\% longer. The mean RTs to sour and sweet substances differ among subjects not only in terms of length, but also order. While for 3 subjects, the mean RTs to acids are shorter than they are to sweeteners, for Subject D it is shorter to sweeteners than to acids. However, the subjects are all alike in that mean RTs to salts are significantly shorter than those to other tastants, and in that mean RTs to bitter are significantly the longest. The difference between the intermediate mean RTs to acids and those to sweeteners is decidedly small, sometimes even under the significance level.

These unequal differences among reaction times with respect to substances with different taste qualities explain why most authors generally agree that, on the anterior part of the tongue, the RT to the salty taste is the shortest and to bitter the longest, while the position for sour and sweet is sometimes interchanged (Bujas, 1935; Kiesow, 1903; Vintschgau \& Hönigschmied, 1875; Yamamoto \& Kawamura, 1981).

Objections that the groups of tastants were not mutually equalized in taste intensity could be raised. The observed differences might therefore be the effect of their unequal subjective efficacy. For this reason we made some additional measurements, trying, for each quality, to obtain its irreducible minimum. In these measurements, for each taste quality, we used one or two substances, each in three very strong concentrations. The shortest RT was taken as the chronobasis (irreducible minimum), which, in the majority of cases, was not linked to the strongest stimulus applied.
The mean values $(M \pm S D)$ obtained for 3 new subjects (with about 25 trials per substance and per subject) were $373 \pm 58.86$ for salts $(\mathrm{NaCl}, \mathrm{LiCl}) ; 559 \pm 107.61$ for acids ( $\mathrm{HCl}$, citric acid); $602 \pm 89.18$ for sweeteners (sucrose, saccharin) and $864 \pm 159.60$ for $\mathrm{QHCl}$. These values substantially agree with the results obtained using withintaste-quality matched solutions.

The statistically significant differences among RTs to substances that elicited four basic tastes (except, sometimes, those between sour and sweet) indicate that the time primarily spent in the peripheral transduction process on four receptor types is different. These differences are presumably connected to the unequal temporal summation of the stimulus effects necessary to activate four different types of receptors. After all, similar differences were found in the relationship between the taste-stimulus duration and buildup times (Bujas \& Ostojčić, 1939).

For the sense of taste, the interindividual differences in RT are generally larger than those for other sensory modalities. The gustatory RTs of different subjects in response to the same stimulus can even differ by a factor of one to three times. Unfortunately, the RTs for the same individual also vary widely from trial to trial, although this intravariability is smaller than the RT intervariability, and the shift in RTs from day to day is generally in the same direction for all the taste stimuli applied. The mean values of the RT intravariability for our subjects, regardless of the tastant quality, amounted to $16.4 \%$, which is more than the RT intravariability of about $10 \%$ reported for hearing (Chocholle, 1948) or 13\% observed for vision (Steinman, 1944). A strict control of stimulus intensity, stimulated area, stimulus duration, hydrodynamic pressure, stimulus intervals, rinsing time, and tongue movements can reduce the RT intravariability in a single session, but the major sources of a subject's variability-oscillations in attention and changes in the preparatory set-are hard to avoid.

\section{REFERENCES}

BeIDLER, L. (1971). Taste receptor stimulation with salts and acids. In L. Beidler (Ed.), Handbook of sensory physiology: Vol. $I V$. Chemical senses: Pt. 2. Taste (pp. 200-220). Berlin-Heidelberg-New York: Springer Verlag.

Beidler, L., \& Tonosakı, K. (1985). Multiple sweet receptor sites and taste theory. In D. Pfaff (Ed.), Taste, olfaction and the central nervous system. A festschrift in honor of Carl Pfaffimann (pp. 47-64). New York: Rockefeller University Press.

Bujas, Z. (1935). Le temps de réaction aux excitations gustatives d'intensité différente. Comptes Rendus des Séances de la Societé de Biologie, 119, 1360-1362.

Bujas, Z. (1980). Reaction time as a tentative measure of taste intensity. In $\mathrm{H}$. van der Starre (Ed.), Olfaction and taste VII (pp. 363366). London: IRL Press.

Bujas, Z., \& Ostojčı́c, A. (1939). L'évolution de la sensation gustative en fonction du temps d'excitation. Acta Instituri Psychologici Universitatis Zagrebensis, 3, 1-24.

Bujas, Z., Szabo, S., Mayer, D., Ajduković, D., \& Vodanović, M. (1989). Reaction time as a tentative measure of taste intensity and of taste mixture effects. Acta Biologica JAZU, 14, 17-37. 
CHOCHOLLE, R. (1948). Quelques remarques sur les variations et la variabilité des temps de réaction auditifs. Journal de Psychologie Normale et Pathologique, 41, 345-358.

HahN, H. (1949). Beiträge zur Reizphysiologie. Heideiberg: Scherer.

HALPERN, B. (1986). Constraints imposed on taste physiology by human taste reaction time data. Neuroscience \& Biobehavioral Reviews, 10, 135-151.

KIEsow, F. (1903). Ein Beitrag zur Frage nach den Reaktionszeiten der Geschmacksempfindungen. Zeitschrift für Psychologie \& Physiologie der Sinnesorgane, 33, 453-461.

LAwLESS, H. \& Stevens, D. (1983). Cross adaptation of sucrose and intensive sweeteners. Chemical Senses, 7, 309-315.

McBurney, D. H., Smith, D. V., \& SHICK, T. R. (1972). Gustatory cross adaptation: Soumess and bitterness. Perception \& Psychophysics, 11, 228-232.

SChIFFMAN, S., CAHN, H., LiNDLEY, M. (1981). Multiple receptor sites mediate sweetness: Evidence from cross adaptation. Pharmacology, Biochemistry, \& Behavior, 15, 377-388.

Smith, D. V., \& MCBurNEY, D. H. (1969). Gustatory cross adapta- tion: Does a single mechanism code the salty taste? Journal of $E x$ perimental Psychology, 80, 101-105.

Steinman, A. (1944). Reaction time to change compared with other psychophysical methods. Archives of Psychology, 292, 34-60.

Vintschgau, M., \& Hönigschmed, J. (1875). Versuche über die Reactionszeit einer Geschmacksempfindung. Archiv fitr die Gesamte Physiologie, 10, 1-48.

Yamamoto, T., Kato, T., Matsuo, R., Kawamura, Y., \& Yoshida, M. (1985). Gustatory reaction time to various sweeteners in human adults. Physiology \& Behavior, 35, 411-415.

Yamamoto, T., \& Kawamura, Y. (1981). Gustatory reaction time in human adults. Physiology \& Behavior, 26, 715-719.

Yamamoto, T., \&awamuRA, Y. (1984). Gustatory reaction time to various salt solutions in human adults. Physiology \& Behavior, 32, 49-53.

(Manuscript received May 13, 1988; revision accepted for publication October 19, 1988.) 